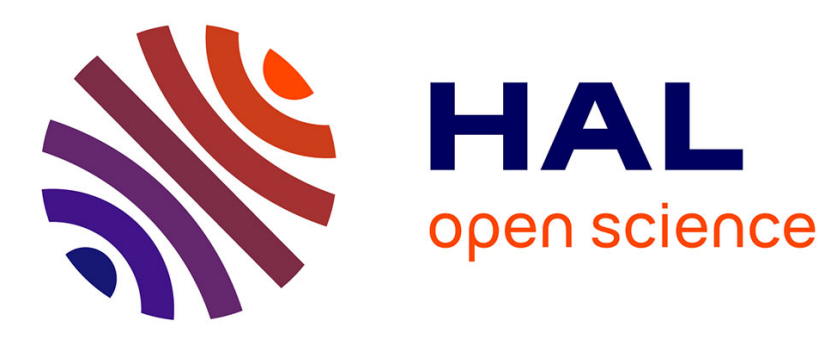

\title{
Opaque interactions between vowel merger and metaphony
}

\author{
Francesc Torres-Tamarit, Kathrin Linke
}

\section{To cite this version:}

Francesc Torres-Tamarit, Kathrin Linke. Opaque interactions between vowel merger and metaphony. Approaches to metaphony in the languages of Italy, 2016. hal-01678363

\section{HAL Id: hal-01678363 https://hal.science/hal-01678363}

Submitted on 9 Jan 2018

HAL is a multi-disciplinary open access archive for the deposit and dissemination of scientific research documents, whether they are published or not. The documents may come from teaching and research institutions in France or abroad, or from public or private research centers.
L'archive ouverte pluridisciplinaire HAL, est destinée au dépôt et à la diffusion de documents scientifiques de niveau recherche, publiés ou non, émanant des établissements d'enseignement et de recherche français ou étrangers, des laboratoires publics ou privés. 


\title{
Opaque interactions between vowel merger and metaphony Francesc Torres-Tamarit and Kathrin Linke
}

\begin{abstract}
Metaphony is a common process in most Italo-Romance varieties, whereby an unstressed high vowel inflectional suffix causes raising of a stressed root vowel. In some varieties, metaphony interacts with a process in which phonetic contrast among a set of suffixes neutralizes (i.e. vowel merger). This paper develops a parallel analysis of two opaque interactions between vowel merger and metaphony in Turbidity Theory, a model assuming containment, combined with privative features and maximal economy in the representation of segments. The basic idea is that metaphony in opaque environments is computed synchronically as a non-local licensing condition of a feature [high] only if it is underlyingly present. On the one hand, overapplication of metaphony is due to prohibiting the realization of a feature [high] lexically linked to a suffix, which needs to be licensed non-locally by associating it with a stressed vowel. On the other hand, underapplication of metaphony is due to insertion of a feature [high] in non-low suffixes, which does not need to be licensed because it is not lexical.
\end{abstract}

\section{Introduction}

Metaphony refers to a phonological process characterizing most Italo-Romance varieties whereby an unstressed high vowel inflectional suffix causes raising of a preceding stressed (mid) root vowel. For instance, Foggiano presents the transparent metaphony case, i.e. that both stressed high-mid and low-mid root vowels alternate with high vowels whenever a high vowel suffix follows (1).

(1) Transparent metaphony in Foggiano (Calabrese 2011)

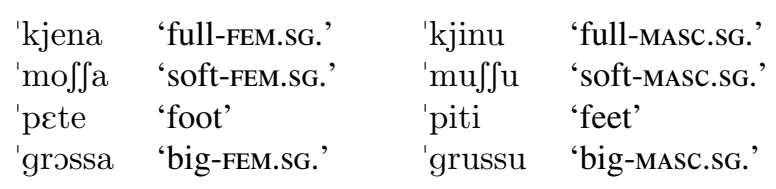

The process of metaphony interacts with a (diachronic) process of vowel merger in some Italo-Romance varieties. Vowel merger describes a situation in which the phonetic contrast among a set of suffixes spelling out different morphosyntactic features is neutralized. The examples in (2) illustrate vowel merger of two nominal and two verbal inflectional suffixes in the present indicative singular in Salentino.

(2) Vowel merger in Salentino (Calabrese 1985, Ribezzo 1912)

$\begin{array}{ccc}\text { Nominal } & \{[\text { MASCULINE }] \&[\text { PlURAL }]\} & \{[\text { FEMININE }] \&[\text { PLURAL }]\} \\ \text { suffixes } & {[\mathrm{i}]} & {[\mathrm{i}]} \\ & & \\ \text { Verbal } & \{[2 \text { PERSON }] \&[\text { SINGULAR }]\} & \{[3 \text { PERSON }] \&[\text { SINGULAR }]\} \\ \text { suffixes } & {[\mathrm{i}]} & {[\mathrm{i}]}\end{array}$

For Italo-Romance systems with vowel merger, vowel suffixes might be merged in favor of high vowels or in favor of non-high vowels, usually a schwa. From a serial ordered-rule perspective, in all these varieties metaphony precedes vowel merger. However, metaphony overapplies or underapplies depending on whether a metaphonic trigger becomes opaque or a metaphony-neutral segment becomes an alleged trigger in surface representations (3). 
(3) Vowel merger - metaphony interactions

\begin{tabular}{lll} 
& System A (cf. Arpinate 2.1) & System B (cf. Salentino 2.2) \\
\hline \multirow{3}{*}{ Metaphony } & /Underlying trigger/ & /Underlying blocker/ \\
Vowel merger & $\checkmark$ & - \\
& $\checkmark$ (in favor of a non-high vowel) & $\checkmark$ (in favor of a high vowel) \\
& [Surface opaque triggering suffix] & [Surface opaque blocking suffix] \\
\hline & OvERAPPLICATION & UNDERAPPLICATION
\end{tabular}

In this paper, an analysis of the two systems schematized in (3) will be developed, couched within the formalism of Turbidity Theory (TT, Goldrick 2001, Van Oostendorp 2008), a constraint-based model assuming containment and using parallel computation.

In TT, the lexical association between a phonological feature and a root node is always contained in output representations. Associations between lexical features and root nodes are represented by $\uparrow$ (projection relation); associations between surface features and root nodes are represented by $\downarrow$ (pronunciation relation). In (4), an input-output mapping is illustrated, in which the phonological feature $F$ is realized locally on the surface, that is, by the root node $r$ that projects the feature $F$.

(4) Local feature-root node association<smiles>FC(I)I</smiles>

We will propose, however, that phonological features can also be realized non-locally, that is, licensed at a distance by root nodes other than those that project them. A non-local input-output mapping is illustrated in (5), where a phonological feature $F$ is pronounced by a root node $s$ although it is projected by a root node $r$.

(5) Non-local feature-root node association<smiles>FC(I)I</smiles>

We assume a form of substance-freedom in the following terms: first, phonological features are privative (cf. Harris and Lindsey 1995 and references therein) and the representation of segments is maximally economic, i.e. segments are specified for the number of features necessary to capture their phonological activity and patterning, and not for more features (Dresher 2009). Second, two instances of the same phonetic output may have two different phonological output representations due to whether a segment is derived or non-derived.

The basic claim of this paper is that metaphony in opaque environments is computed synchronically as a non-local licensing condition of a feature [high] only if it is underlyingly present, as shown in (5). On the one hand, overapplication of metaphony is due to prohibiting the realization of a feature [high] that is lexically linked to a suffix, which consequently needs to be licensed non-locally by associating it with a stressed vowel. On the other hand, underapplication of metaphony is due to insertion of a feature [high] in non-low suffixes, which does not need to be licensed because it is not lexical.

This paper is organized as follows. In $\S 2$, data from two Italo-Romance varieties are presented, namely Arpinate and Salentino, which show different opaque environments. The representational assumptions and the formalization of constraints used in the analysis are explained in $\$ 3$. $\$ 4$ is devoted to show how the opaque data can be accounted for using TT with privative features. $\S 5$ briefly concludes. 


\section{Data}

The underlying vowel system of most Italo-Romance varieties consists of seven vowels, with a twoheight distinction in the mid region (6).

(6) Italo-Romance varieties' 7-vowel system

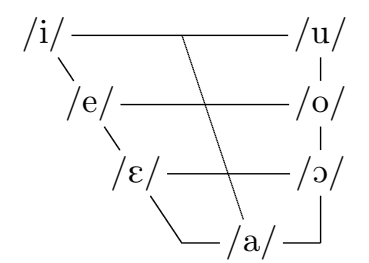

\subsection{Arpinate}

In Arpinate (Lazio), all nominal suffixes except for class I feminine singular correspond to surface schwas. Being non-high suffixes, these schwa morphs are expected not to trigger metaphony, but some of them do, namely both class II suffixes and the class III plural suffix (7). The data are taken from Calabrese (1998), who cites Parodi (1892).

(7) Nominal suffixes and metaphonic alternations (Calabrese 1998, Parodi 1892)

\begin{tabular}{lll|} 
classes & sg. & pl. \\
I (mostly fem.) & - a & - - \\
II (mostly masc.) & no metaphony & no metaphony \\
& $-\partial$ & $-ə$ \\
III (both fem. \& masc.) & metaphony & metaphony \\
& $-\partial$ & $-ə$ \\
\hline
\end{tabular}

Some examples are given in (8) and (9), in which opaque forms in both nominal and verbal paradigms show overapplication of metaphony (within boxes). High-mid vowels raise to high, and low-mid vowels undergo a one-step raising to high-mid and also diphthongize.

(8) Adjectival endings and metaphonic alternations (class I/II)

sg. pl. sg. pl.

\begin{tabular}{lllllll} 
fem. & 'sola & 'solə & 'alone' & 'nera & 'nerə & 'black' \\
masc. & 'sulə & 'sulə & & 'nirə & 'nirə & \\
fem. & 'bona & 'bonə & 'good' & 'vekkja & 'vekkjə & 'old' \\
masc. & 'bwonə & 'bwonə & & 'vjekkjə & 'vjekkjə & \\
\cline { 2 - 3 } & & & &
\end{tabular}

(9) Verbal endings and metaphonic alternations (present indicative)
2. sg. 3. sg
2. sg. 3. sg
'vidə 'vedə 'you see / (s)he sees'
'sjentə 'scntə 'you feel / (s)he feels'
'kurrə 'korrə 'you run / (s)he runs'

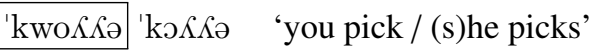


In Arpinate, overapplication of metaphony is due to 'opaque triggers' (i.e. seemingly metaphony-neutral segments due to vowel merger to schwa). ${ }^{1}$

\subsection{Salentino}

In Salentino (Puglia), two front high vowel adjectival suffixes exist ([-i]), one for feminine plural and one for masculine plural. However, only the masculine plural suffix causes metaphony (10). The data are taken from Calabrese (1985), who cites Ribezzo (1912).

(10) Adjectival endings and metaphonic alternations I

sg.

fem.

masc.

$-\mathrm{a}$

no metaphony

metaphony pl.

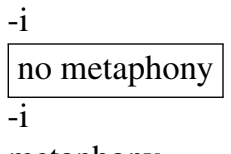

metaphony

Some examples are given in (11), where words within boxes contain a front high vowel suffix that does not cause raising of a preceding mid vowel. In cases where metaphony does apply, high-mid vowels raise to high, and low-mid vowels show diphthongization, as in Arpinate, but do not raise one-step to high-mid. Furthermore, low-mid back vowels (['o]) alternate with ['we].

(11) Adjectival endings and metaphonic alternations II

\begin{tabular}{|c|c|c|c|c|c|c|}
\hline \multirow{3}{*}{$\begin{array}{l}\text { fem. } \\
\text { masc. }\end{array}$} & sg. & pl. & \multirow{3}{*}{ 'cold' } & sg. & pl. & \multirow{3}{*}{ 'hairy' } \\
\hline & 'fredda & 'freddi & & pi'losa & pi'losi & \\
\hline & 'friddu & 'friddi & & pi'lusu & pi'lusi & \\
\hline em. & $\begin{array}{l}\text { 'lenta } \\
\text { 'lisntt }\end{array}$ & \begin{tabular}{|l|} 
'lenti \\
'lienti
\end{tabular} & 'slow' & $\begin{array}{l}\text { 'bona } \\
\text { 'bwenu }\end{array}$ & 'boni & go \\
\hline
\end{tabular}

The same situation is found for nouns, as shown in (12), where singular forms, although ending in a high vowel suffix, do not undergo metaphony.

(12) Noun endings and metaphonic alternations

\begin{tabular}{|c|c|c|c|c|c|}
\hline esi & misi & 'month(s)' & 'tori & 'turi & 'tower(s) \\
\hline 'peti & 'pjeti & 'foot/feet' & 'kori & 'kweri & 'heart(s)' \\
\hline
\end{tabular}

In Salentino, metaphony underapplies due to 'fake metaphonic triggers' (i.e. deceptive triggers due to vowel merger to high).

\footnotetext{
${ }^{1}$ Throughout this paper, the term vowel merger is used instead of vowel reduction because no direct morpho-phonological alternations exist in the domain of inflectional suffixes, as they are always unstressed.
} 


\section{Theory}

\subsection{Representations}

We propose to specify vowels in Arpinate and Salentino as in (13), based on Dyck (1995) for ItaloRomance.

(13) Surface vowel feature specifications

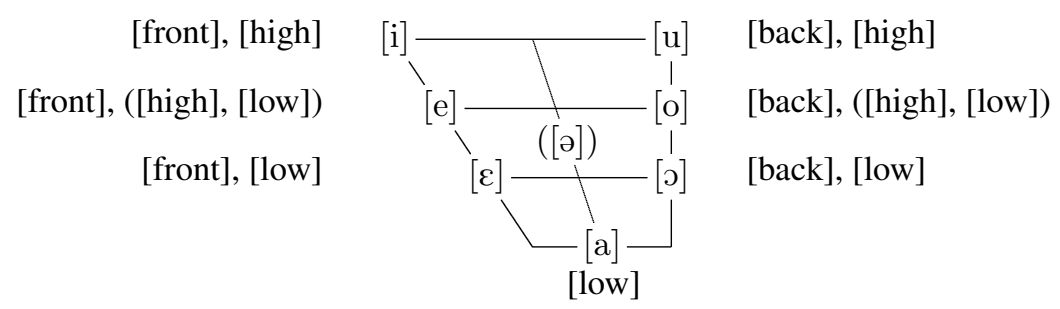

To characterize the surface eight-vowel system in (13), a total of four privative phonological features have been used: two height features, [high] and [low], and two place features, [front] and [back]. Only three features are actually needed to specify a maximally economical eight-vowel inventory $\left(2^{3}\right)$. However, since the two sets of front and back vowels (i.e. except for $ə$ and a) with three height levels each act in complete symmetry, a fourth feature is needed to capture the observed patterning of the vowel system at hand.

High-mid vowels are minimally specified by a place feature, either [front] or [back]. However, if derived from low-mid vowels, we assume that besides the place feature, they also contain the feature [low], inherited from low-mid vowels, and the feature [high], from high vowels. Schwas are unspecified.

Although we use standard feature labels like [high] and [low], we should emphasize that their phonetic content does not play a direct role in phonological computation. We prefer to think of phonological features as being similar to colors in the sense that they can be mixed to create more complex segments, as elements in Element Theory (Harris and Lindsey 1995, Backley 2011). This is why [high] and [low], for instance, can freely surface together to create a derived intersecting segment, in this case a high-mid vowel.

\subsection{Constraints}

In TT, a family of constraints called REcIPRocity (14) ensures that associations between lexical features and root nodes (projection relations $\uparrow$ ) are realized locally in surface representations (pronunciation relations $\downarrow)(14)$.

(14) Reciprocity (Van Oostendorp 2008)

a. $\operatorname{RecipRocity}_{F}^{r}\left(\mathcal{R}_{F}^{r}\right)$ : assign a violation mark for every feature $F$ projected by a root node $r$ that is not pronounced by $r$.

b. $\operatorname{ReCIPROCITY}_{r}^{F}\left(\mathcal{R}_{r}^{F}\right)$ : assign a violation mark for every feature $F$ pronounced by a root node $r$ that is not projected by $r$.

To allow associations between features and root nodes to be realized non-locally, we propose a new family of constraints, LicENSING (15), which is a less stringent version of RECIPROCITY.

\section{(15) LicENSING}

a. Licensing $\uparrow F(\mathcal{L} \uparrow F)$ : assign a violation mark for every projection relation $\uparrow$ of a feature $F$ that does not correspond to some pronunciation relation $\downarrow$ of $F$.

b. Licensing $\downarrow F(\mathcal{L} \downarrow F)$ : assign a violation mark for every pronunciation relation $\downarrow$ of a feature $F$ that does not correspond to some projection relation $\uparrow$ of $F$.

Regarding the operations performed by Gen in TT, recall that projection relations are always contained in output forms; Gen only disposes of the set of operations in (16). 
(16) Gen operations

a. Insertion of a pronunciation relation $\downarrow$

b. Insertion of a feature $F$ together with its pronunciation relation $\downarrow$

With respect to unfaithful mappings, these can be the result of two different scenarios: non-pronunciation of a projected feature, and pronunciation of a non-projected feature. On the one hand, non-pronunciation is triggered by the satisfaction of feature co-occurrence constraints of the type $*\{\mathrm{~F}, \mathrm{G}\}$ with the special case $* \mathrm{~F}$ (Levelt and Van Oostendorp 2007, Van Oostendorp 2014) (17).

(17) Markedness constraints

a. *F: assign a violation mark for every pronunciation of the feature $F$.

b. * $*$ F,G $\}$ : assign a violation mark for every pronunciation of the features $F$ and $G$ by the same root node.

On the other hand, an unfaithful mapping can also arise from the pronunciation of a non-projected feature $G$, which is enforced by the presence of another feature $F$. This situation is induced by implicational constraints (Van Oostendorp 2014) (18).

(18) Implicational constraint

F $\supset$ G: assign a violation mark for every root node that pronounces a feature $F$ and does not pronounce a feature $G$.

\subsection{The metaphony-triggering constraint}

Metaphony has traditionally been treated as a specific case of vowel harmony. In OT, vowel harmony has been attributed to several different constraints: spreading, alignment, sharing, agreement by correspondence (see Gafos and Dye 2011, Rose and Walker 2011 for a review) and feature-validation (Nevins 2010). It is not the purpose of this paper to evaluate these different constraints. An alternative view of metaphony has been developed by Walker (2005). According to her, metaphony has a functional basis in the sense that it improves the perceptibility of the feature [+high] in a posttonic position by associating it with a perceptually stronger position, a stressed syllable (19).

(19) Walker's (2005) metaphony-triggering constraint

License([+high] $)_{\text {Posttonic, }} \sigma$ : [+high] in a posttonic syllable must be associated with a stressed syllable.

A functional motivation for metaphony is plausible. However, after (diachronic) vowel merger, the motivation for metaphony as proposed in Walker (2005) cannot be interpreted by language learners as driven by functional forces anymore.

We take Walker's analysis as the starting point of our proposal. However, we claim that, in the synchronic grammar, metaphony is re-interpreted as a non-local licensing condition in terms of projection relations, as in (20).

(20) Metaphony-triggering constraint as a licensing constraint

Licensing $\uparrow[\text { high }]_{\text {NonFTHD }} /$ FTHD $\left(\mathcal{L} \uparrow[h i g h]_{\text {NonFTHD }}\right)$ : assign a violation mark for every projection relation $\uparrow$ of a feature [high] in a word-final, non-foot head position, that does not correspond to some pronunciation relation $\downarrow$ of [high] in a foot head position. 
It seems reasonable to see the chronology of the facts as follows. First, functional motivations like perception pressures drive metaphony. Speakers start producing gradual shifts of articulation in mid vowels when preceding high vowel suffixes as a way to enhance the cues of high vowels in unstressed position. Later on, learners re-interpret the input as a categorical distinction between two sets of root vowels. At this point, the synchronic grammar builds a metaphony-triggering constraint in terms of pronunciation relations. After this, a different process starts operating in the language, namely vowel merger, probably driven by functional motivations, too. Therefore, speakers start merging different sets of suffixes, while still displaying metaphony, as it was acquired as a phonological rule. Following, in the absence of a clear distinction among sets of different suffixes, learners re-formulate the metaphony-triggering constraint as a licensing constraint in terms of projection relations, instead of pronunciation relations. Assuming that such a scenario was true, this particular case of opacity resulting from sound change can be handled synchronically by parallel grammars with the help of TT. Grammars would allow for stating linguistic generalizations at two distinct levels: at an abstract, lexical one, and also at a concrete, surface one. A model like this is reminiscent of Evolutionary Phonology (Blevins 2004), a formal model of sound change in which phonetic variation and misperception play a key role in accounting for attested sound patterns in natural language, in which notions like markedness or naturalness have no place in synchronic grammars. We assume the idea, at least, that phonology has the ability to translate notions such as 'phonetic perceptibility' (as put forward in Walker 2005) as a condition on projection relations when sound change is obscuring a structural environment. A projection relation is a pure grammatical, function-free notion. Phonology, as an independent module of grammar, should only make use of its own vocabulary. This position precisely allows for explaining phonological opacity as a mismatch between phonetics and phonology (Hamann 2014).

\section{Analysis}

\subsection{Arpinate}

Before going into the details of the analysis, the underlying representations of metaphonic triggers and metaphony-neutral segments must be discussed. Recall that in Arpinate, some schwa suffixes trigger metaphony contrary to what one would expect. For transparent, non-metaphonic schwa suffixes, either a representation with a place feature or without any feature at all is consistent with the facts. As long as this kind of suffixes lack the feature [high], metaphony is not triggered. From now on, where place distinctions are not relevant, we will use the cover feature [PLACE]. In (21), the underlying representation of a non-metaphonic nominal suffix in Arpinate is represented, with abstract morphosyntactic features such as class and number associated with a root node, which in turn projects its phonological features. Parentheses express the fact that a specific feature can be absent from the representation in accordance with the Richness of the Base hypothesis (Prince and Smolensky 1993).

(21) Underlying representation of a non-metaphonic nominal suffix

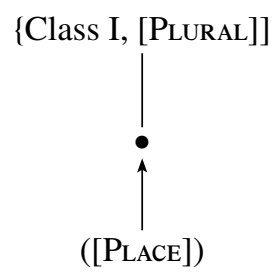


For a metaphonic triggering suffix in Arpinate, the feature [high] is projected (22).

(22) Underlying representation of a metaphonic nominal suffix

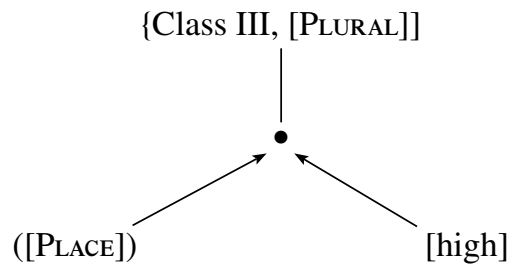

In Arpinate, suffixes are restricted to low vowels and schwa. This means that no place features can surface in the suffixal domain. A markedness constraint like $*\left[\right.$ PLACE $_{\text {NonFootHeaD }}$, prohibiting the pronunciation of a place feature in a word-final, non-foot head position, must therefore be top-ranked. In case a place feature is present in the input, as in tableau (23), the constraint $*[\text { Place }]_{\text {NonFootHead }}$ prevents this feature from being pronounced, as shown by candidate (c). ${ }^{2}$ Candidate (a) and candidate (b) satisfy $*[\text { Place }]_{\text {NonFootHead }}$, but candidate (b) fatally violates $*[\text { high }]_{\text {NonFootHead }}$, which disfavors the pronunciation of a feature [high] in word-final, non-foot head position. The feature [high], not present underlyingly, is therefore inserted in candidate (b). If a feature [high] is pronounced and the place feature is left unpronounced, a central high vowel is generated, which is absent from the sound inventory of Arpinate. In the absence of the feature [high] in word-final, non-foot head position, no metaphony is expected. The most harmonic candidate is candidate (a), in which the place feature is left unpronounced, which incurs a violation of low-ranked Reciprocity ${ }_{[\text {Place }]}^{V}$ NonFootHead, which states that every place feature projected by a vocalic root node should be pronounced by the same vocalic root node. By comparing these candidates, two ranking arguments are discovered: both $*[\text { Place }]_{\text {NonFootHead }}$ and $*[\text { high }]_{\text {NonFootHead }}$ dominate Reciprocity $_{[\text {Place }]}^{V} /$ NonFootHead ${ }^{3}$

(23) Non-metaphonic (transparent) -ə

\begin{tabular}{|c|c|c|c|}
\hline 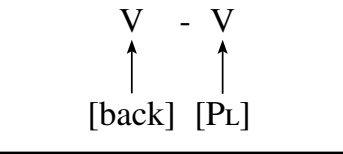 & $*[\mathrm{PL}]_{\mathrm{NoNFTHD}}$ & *[high $]_{\text {NoNFTHd }}$ & $\mathcal{R}_{[\mathrm{PL}]}^{V} / \mathrm{NonFTHD}_{\mathrm{T}}$ \\
\hline 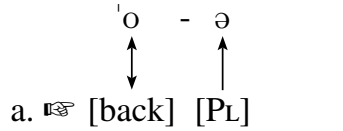 & & $\begin{array}{l}i \\
i \\
i \\
i\end{array}$ & $*$ \\
\hline b. $\stackrel{\downarrow}{\text { back }]}_{[\text {high }][\mathrm{PL}]}^{\mathrm{o}}$ & & $\begin{array}{c}1 \\
1 \\
1 \\
1 \\
1\end{array}$ & $*$ \\
\hline 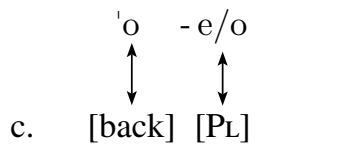 & $* \mathrm{~W}$ & & $\mathrm{~L}$ \\
\hline
\end{tabular}

For opaque, metaphonic schwa suffixes, however, an underlying feature [high] is present in the underlying representation. In tableau (24), a potential feature [Place] projected by the suffix is not included

\footnotetext{
${ }^{2}$ Tableaux are presented in comparative format, and also include traditional violation marks. A capital $\mathrm{W}$ is entered into the cell of a particular loser row if the winner is favored over that loser by the constraint in that column. A capital L is inserted in the opposite situation, that is, if that loser is favored over the winner. Nothing is inserted if neither the winner nor a particular loser are favored by a specific constraint. Every L must be dominated by at least one W in comparative tableaux, meaning that every loser-favoring constraint is dominated by at least one winner-favoring constraint.

${ }^{3} \mathrm{~A}$ candidate in which both [high] and [PLACE] are pronounced would also violate the feature co-occurrence constraint $*\{[$ high $],[$ Place $]\}$, which conflates the two independently motivated constraints presented in tableau (23).
} 
for clarity (this would be consistent with the Richness of the Base hypothesis). As seen in the previous tableau, the feature [high] can never surface due to top-ranked $*[\text { high }]_{\text {NonFootHeAD }}$, which forces all non-low suffixes to surface as schwas. Thus, ${ }^{*}[\text { high }]_{\text {NonFootHead }}$ rules out candidate (c), and dominates Reciprocity $V$ [high] $/$ NonFootHead, which allows suffixes projecting a feature [high] to leave this feature unpronounced. The difference between candidate (a) and candidate (b) is that the latter violates LicensING $\uparrow[\text { high }]_{\text {NonFootHead }} /$ FootHead. This is the metaphony-triggering constraint defined in (20), which forces a projected feature [high] in word-final, non-foot head position, to be non-locally licensed via pronunciation by the stressed root vowel. The winning candidate is therefore candidate (a), with metaphony, which violates $\operatorname{RECIPROCITY}_{V}^{[h i g h]}$, as the stressed root vowel pronounces a feature [high] that is not projected by its root node. To sum up, the feature [high] lexically associated with the suffix vowel cannot be pronounced in this position due to top-ranked $*[\text { high }]_{\text {NonFootHead }}$. However, it must be pronounced by the stressed root vowel in order to satisfy Licensing $\uparrow[\text { high }]_{\text {NonFootHead }} /$ FootHead.

(24) Metaphonic (opaque) -ə

\begin{tabular}{|c|c|c|c|c|}
\hline$\underset{\uparrow}{\mathrm{V}}-\underset{\text { [back] [high] }}{\mathrm{V}}$ & $*[\text { high }]_{\text {NONFTHd }}$ & $\begin{array}{l} \\
1 \\
\mathcal{L} \uparrow[\text { high }]_{\text {NonFTHd }}\end{array}$ & $\mathcal{R}_{V}^{[h i g h]}$ & \begin{tabular}{c}
$\mathcal{R}_{[h i g h]}^{V} / \mathrm{NONFTHD}_{\mathrm{T}}$ \\
\hdashline
\end{tabular} \\
\hline a. & & $\begin{array}{c}7 \\
\vdots \\
1 \\
1\end{array}$ & $*$ & $\begin{array}{c}1 \\
\vdots \\
\vdots \\
1\end{array}$ \\
\hline 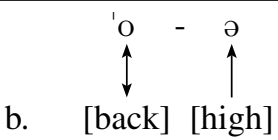 & & $\begin{array}{c}1 \\
1 \\
1 \\
1 \\
1 \\
1\end{array}$ & $\mathrm{~L}$ & $\begin{array}{c}3 \\
\vdots \\
1 \\
1\end{array}$ \\
\hline 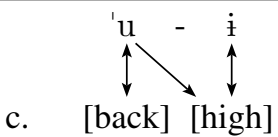 & $* \mathrm{~W}$ & & $*$ & $\mathrm{~L}$ \\
\hline
\end{tabular}

\subsection{Salentino}

In Salentino, the nominal metaphonic suffixes contain the feature [high] and a place feature, [front] for masculine singular, and [back] for masculine plural (25).

(25) Underlying representation of two metaphonic nominal suffixes

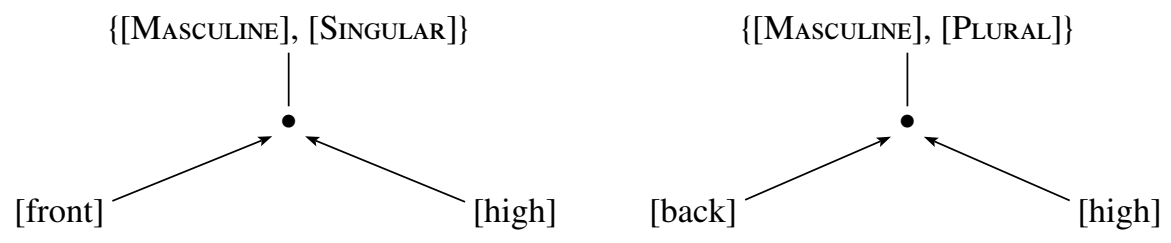

As opposed to Arpinate, the feature [high] must be pronounced in word-final, non-foot head posi-

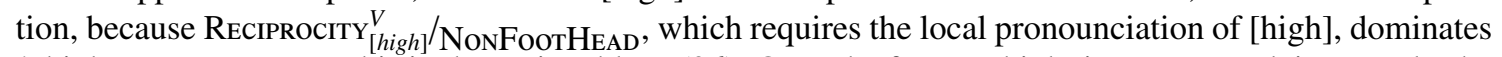
* $[\text { high }]_{\text {NonFootHead }}$. This is shown in tableau (26). Once the feature [high] is pronounced, it must also be licensed non-locally to satisfy the metaphony-triggering constraint, Licensing $\uparrow[\text { high }]_{\text {NonFootHead }} /$ FootHead. The most harmonic candidate, candidate (a), only violates Reciprocity ${ }_{V}^{[h i g h]}$ and *[high]/NonFootHead 
(26) Metaphonic (transparent) high vowel suffix

\begin{tabular}{|c|c|c|c|c|}
\hline$\uparrow_{[\text {front }]}^{\mathrm{V}}-\overbrace{[\text { high] }][\text { back] }}^{\mathrm{V}}$ & $\mathcal{R}_{[h i g h]}^{V} /$ NonFTHD & 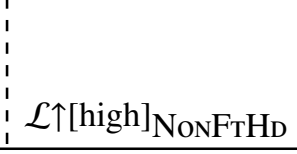 & $\mathcal{R}_{V}^{[h i g h]}$ & 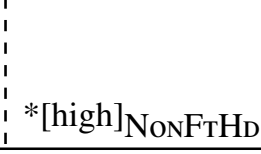 \\
\hline a. & & I & $*$ & $\begin{array}{c}y_{1} \\
\vdots \\
\vdots \\
1\end{array}$ \\
\hline $\begin{array}{l}\downarrow \\
\text { b. } \quad \text { [front] }\end{array}$ & & $* \mathrm{~W}$ & $\mathrm{~L}$ & $\begin{array}{c}1 \\
\vdots \\
\vdots \\
1\end{array}$ \\
\hline$\left.\uparrow_{[\text {front }]}^{\text {'e }}\right|_{[\text {high }][\text { back }]} ^{\mathrm{o}}$ & $* \mathrm{~W}$ & ! & $\mathrm{L}$ & $\begin{array}{c}1 \\
\vdots \\
\vdots \\
1\end{array}$ \\
\hline
\end{tabular}

For the opaque, non-metaphonic high vowel nominal suffix, the feature [high] is absent from the underlying representation, which only contains the feature [front]. This suffix corresponds to feminine plural (27).

(27) Underlying representation of a metaphonic nominal suffix

$\{[$ Feminine], [PluraL $]\}$

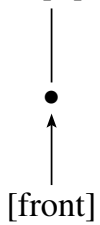

However, this suffix, which only contains the feature [front], surfaces as a high vowel. This is due to the insertion of the feature [high] triggered by the satisfaction of the constraint [PLACE] $\supset[$ high]/NonFootHEAD.

So far we have shown two different types of vowel merger. The one operating in Arpinate is due to deletion of the feature [high], and the one operating in Salentino is due to insertion of the feature [high]. These two types of vowel merger are the result of two different markedness constraints, *F, and an implicational constraint $\mathrm{F} \supset \mathrm{G}$, respectively. ${ }^{4}$

As illustrated in tableau (28), vowel merger to high in Salentino is the result of satisfying the implicational constraint demanding the pronunciation of [high] in the presence of [PLACE]. This means that in word-final, non-foot head positions, all non-low suffixes must be high vowels. This inserted feature [high] has no projection relation, and this is why it vacuously satisfies the metaphony-triggering constraint (not included in the tableau below). However, we still have to account for the fact that metaphony does not overgenerate in this case. The answer is straightforward. Metaphony would imply a double pronunciation of the feature [high], as in candidate (b), which gratuitously violates License $\downarrow$ high] twice, requiring any pronunciation of the feature [high] to correspond to some projection relation, and RecIPRociTY ${ }_{V}^{[h i g h]}$ twice. Thus, candidate (b) is harmonically bounded by candidate (a). In other words, insertion of [high] is minimally required to comply with vowel merger, but metaphony is unmotivated if the feature [high] is inserted (i.e. derived). ${ }^{5}$

\footnotetext{
${ }^{4}$ The latter type of vowel merger consisting of addition of a feature contradicts the way vowel reduction processes are understood in Element Theory, which is seen as reduction of the number of elements in prosodically weak positions. However, it is clear that in Salentino the feature [high] is not underlying, as it blocks metaphony.

${ }^{5}$ The analysis has focused on high-mid vowel targets, which raise to high when affected by metaphony. When the target is a low-mid vowel, however, we get diphthongization in Salentino $\left(/ \varepsilon, \mathrm{o} / \rightarrow\left[{ }^{\prime} \mathrm{j} \varepsilon\right.\right.$, 'jo] $\left.]\right)$. This outcome can be analyzed as the effect of
} 
(28) Non-metaphonic (opaque) high vowel suffix

\begin{tabular}{|c|c|c|c|c|}
\hline$\underset{\text { [front] [front] }}{\uparrow}-\underset{\uparrow}{\mathrm{V}}-\underset{1}{\mathrm{~V}}$ & {$[\mathrm{PL}] \supset[$ high $] /$ NonFTHD } & $\mathcal{R}_{\left[\mathrm{PL}_{\mathrm{L}}\right.}^{V} / \mathrm{NoNFTHD}_{\mathrm{T}}$ & $\mathcal{L} \downarrow[$ high $]$ & $\begin{array}{l}\mathcal{R}_{V}^{[h i g h]} \\
\end{array}$ \\
\hline 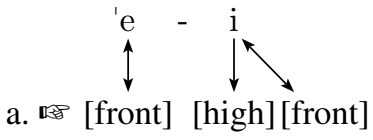 & & & $*$ & $\begin{array}{c}\vdots \\
\vdots \\
1 \\
1 \\
1\end{array}$ \\
\hline b. [front] [high][front] & & & $* * \mathrm{~W}$ & $\begin{array}{ll} \\
\vdots \\
1 \\
1 \\
1\end{array}$ \\
\hline 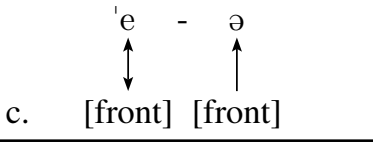 & & $* \mathrm{~W}$ & L & $\begin{array}{c}1 \\
\vdots \\
1 \\
1 \\
1\end{array}$ \\
\hline 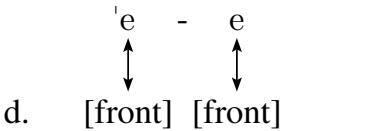 & $* \mathrm{~W}$ & $\begin{array}{l}1 \\
1 \\
1 \\
1 \\
1\end{array}$ & $\mathrm{~L}$ & $\begin{array}{c}1 \\
\vdots \\
\vdots \\
1 \\
1\end{array}$ \\
\hline
\end{tabular}

\section{Conclusions}

This paper has presented a unified account of two types of opaque interactions between vowel merger and metaphony in Arpinate and Salentino, which supports feature privativity and Turbidity Theory. A new family of constraints has been proposed, LicENSING, together with markedness constraints of the cooccurrence type and the implicational type. The basic idea put forward in this paper is that metaphony in opaque environments is computed synchronically as a non-local licensing condition of a feature [high] only if underlying. On the one hand, overapplication of metaphony, as in Arpinate, is due to prohibiting the realization of a feature [high] lexically linked to a suffix, which therefore needs to be licensed nonlocally by being pronounced by a stressed vowel. On the other hand, underapplication of metaphony, as in Salentino, is due to insertion of a feature [high] in non-low suffixes, which does not therefore need to be licensed because it is not lexical.

This Turbidity Theory analysis is in line with other studies acknowledging the existence of dissimilarities between phonology and phonetics (Hamann 2014, Blaho 2008, Odden 2006), and it aims at contributing on a theoretical level to the discussion on whether phonological computation abstracts away from phonetic substance.

\section{References}

Backley, P., 2011. An introduction to Element Theory. Edinburgh University Press.

Blaho, S., 2008. The syntax of phonology. A radically substance-free approach. Ph.D. thesis. University of Tromsø.

a feature co-occurrence constraint $*\{[\mathrm{low}],[$ high] $\}$, which prohibits these two features to be pronounced by the same root node. To satisfy $*\{[$ low],[high] $\}$ and also the metaphony-triggering constraint, an extra melodic slot is inserted to host the pronunciation of the feature [high]. However, diphthongization co-occurs with a one-step raising of the stressed low-mid vowel in Arpinate, that is, from low-mid to high-mid, according to Calabrese (1998)'s phonetic transcriptions. This partial raising could be better understood as a phonetic co-articulation effect induced by the presence of the high front glide. Moreover, given that no (lexical) contrast exists between ['je] and ['je] in metaphonic environments, it is difficult to see whether this presumed one-step raising is phonological, or a language-particular phonetic implementation of the metaphonic process consisting of adding an extra melodic slot. In any case, discussing the topic of metaphonic chain shifts goes beyond the purpose of this paper. 
Blevins, J., 2004. Evolutionary phonology: The emergence of sound patterns. Cambridge: Cambridge University Press.

Calabrese, A., 1985. Metaphony in Salentino. Rivista di Grammatica Generativa 9-10, 1-140.

Calabrese, A., 1998. Metaphony revisited. Rivista di Linguistica 10, 7-68.

Calabrese, A., 2011. Metaphony in Romance, in: Van Oostendorp, M., Ewen, C., Hume, E., Rice, K. (Eds.), The Blackwell Companion to Phonology. Malden, MA: Wiley-Blackwell, pp. 2631-2661.

Dresher, B.E., 2009. The contrastive hierarchy in phonology. volume 121. Cambridge University Press.

Dyck, C., 1995. Constraining the phonology-phonetics interface, with exemplification from Spanish and Italian dialects. Ph.D. thesis. University of Toronto.

Gafos, A., Dye, A., 2011. Vowel harmony: Opaque and transparent vowels, in: Van Oostendorp, M., Ewen, C., Hume, E., Rice, K. (Eds.), The Blackwell Companion to Phonology. Wiley-Blackwell, pp. 2164-2189.

Goldrick, M., 2001. Turbid output representations and the unity of opacity, in: Hirotani, M., Coetzee, A., Hall, N., Kim, J.y. (Eds.), Proceedings of the North East Linguistics Society. Amherst: GLSA. volume 30, pp. 231-245.

Hamann, S., 2014. Mismatches between phonology and phonetics. Invited talk at the 11th Old World Conference in Phonology.

Harris, J., Lindsey, G., 1995. The elements of phonological representation, in: Durand, J., Katamba, F. (Eds.), Frontiers of phonology: Atoms, structures, derivations. Harlow, Essex: Longman, pp. 34-79.

Levelt, C., Van Oostendorp, M., 2007. Feature co-occurrence constraints in L1 acquisition. Linguistics in the Netherlands 24, 162-172.

Nevins, A., 2010. Locality in vowel harmony. Cambridge: MIT Press.

Odden, D., 2006. Phonology ex nihilo. Talk at the Troms $\varnothing$ Phonology Project Group Meeting.

van Oostendorp, M., 2008. Incomplete devoicing in formal phonology. Lingua 118, 1362-1374.

van Oostendorp, M., 2014. Representing variation: The view from phonological theory. Talk at Theoretical Issues in Contemporary Phonology: Reading Tobias Scheer.

Parodi, E., 1892. Il dialetto di Arpino. Archivo Glottologico Italiano 13, 299-308.

Prince, A., Smolensky, P., 1993. Optimality Theory: Constraint interaction in generative grammar. Unpublished ms., Rutgers University \& University of Colorado, Boulder. Published 2004, Malden, MA; Oxford: Blackwell.

Ribezzo, F., 1912. Il dialetto apulo-salentino di Francavilla Fontana. Martina Franca.

Rose, S., Walker, R., 2011. Harmony systems, in: Goldsmith, J., Riggle, J., Yu, A. (Eds.), The Handbook of Phonological Theory. Wiley-Blackwell, pp. 240-290.

Walker, R., 2005. Weak triggers in vowel harmony. Natural Language \& Linguistic Theory 23, 917-989. 